\title{
The effect of disease activity on thyroid nodules in patients with acromegaly
}

\author{
Seyfullah Kan ${ }^{1)}$, Muhammed Kizilgul ${ }^{1)}$, Bulent Celik $^{2}$, Selvihan Beysel ${ }^{1)}$, Mustafa Caliskan ${ }^{1)}$, \\ Mahmut Apaydin ${ }^{1)}$, Bekir Ucan ${ }^{1)}$ and Erman Cakal ${ }^{1)}$ \\ 1) Department of Endocrinology and Metabolism, Diskapi Teaching and Research Hospital, Ankara, Turkey \\ 2) Department of Statistics, Gazi University, Faculty of Science, Ankara, Turkey
}

\begin{abstract}
Nodular thyroid disease is a very common disorder in patients with acromegaly. Insulin-like growth factor-1 (IGF-1) is a thyroid growth factor, and there is a correlation between IGF-1 levels and thyroid volume (TV) in patients with acromegaly. There is no study investigating the impact of somatostatin analog (SSA) treatment on thyroid nodule volume in patients with acromegaly. We aimed to assess thyroid nodule volume change with SSA treatment in patients with persistent acromegaly. We retrospectively analyzed data from 108 consecutive patients with acromegaly who were followed up by our clinic after undergoing surgery between 2002 and 2014. Patients who were cured after surgery were excluded. We only selected 43 patients ( 21 males, 22 females, mean age $52.8 \pm 11.9$ years) who did not meet the criteria of remission postoperatively, who were treated with SSA for at least six months and had normal thyroid function. Patients were divided into three groups (well-controlled, controlled, and active) according to their IGF-1 and growth hormone (GH) levels. All patients underwent an evaluation of TV and total thyroid nodule volume (TTNV) by ultrasound. TTNV decreased significantly in patients with well-controlled acromegaly $(0.44[0.75]$ to $0.23[0.73], p<0.001)$. TTNV did not change in controlled patients $(0.18$ [1.28] to 0.13 [1.54], $p=0.959)$; however TTNV increased in patients with active acromegaly $(0.77$ [1.46] to 1.03 [1.88], $p=0.028$ ). Successful medical treatment of patients with active acromegaly decreases thyroid nodule volume. Sustained exposure to IGF-1 may cause an increase in thyroid nodule volume in patients with acromegaly.
\end{abstract}

Key words: Thyroid nodule volume, Acromegaly, Somatostatin analog treatment

GOITER is very common in patients with acromegaly, and it can be diffuse or multinodular. In a study of patients with acromegaly, 92\% had an enlarged thyroid gland as determined using ultrasound; the mean thyroid size was increased more than five times than normal [1]. According to a recent meta-analysis, nodular thyroid disease is a very common disorder in patients with acromegaly (prevalence slightly below 60\%) [2]. Tramontano et al. confirmed that insulin-like growth factor-1 (IGF-1) was a thyroid growth factor in vitro [3]. There is a correlation between IGF-1 levels and TV in patients with acromegaly [4]. Data on thyroid volume changes after the successful treatment of acromegaly are contradictory. Some authors confirm that TV is decreased by the reduction of IGF-1 and growth hormone (GH) levels with treatment $[3,5]$. In contrast, Cannavo et al. reported no significant decrease in TV in patients with acromegaly

Submitted Nov. 21, 2018; Accepted Jan. 15, 2019 as EJ18-0502 Released online in J-STAGE as advance publication Feb. 9, 2019 Correspondence to: Seyfullah Kan, MD, Süleyman Demirel University Faculty of Medicine, Department of Internal Medicine, Çünür Doğu Yerleşkesi, Merkez/Isparta 32260, Turkey.

E-mail: seyfullahkan76@hotmail.com followed by a period of 2-7 years [6]. Ongoing exposure to high serum IGF-1 levels may play a role in the development of thyroid nodules in patients with acromegaly [7]. Völzke et al. reported that high serum IGF-1 levels were associated with thyroid nodules [8]. However, there is no study investigating the effect of somatostatin ana$\log$ (SSA) treatment on thyroid nodule volume in patients with acromegaly. The aim of this retrospective study was to evaluate thyroid volume and thyroid nodule volume change with SSA treatment in patients with acromegaly.

\section{Material and Methods}

\section{Subjects selection and measurements}

We retrospectively analyzed data from 108 consecutive patients with acromegaly who were followed up by our clinic after undergoing surgery between 2002 and 2014. Patients who were cured after surgery were excluded. Cure is currently defined as normal age-adjusted IGF-1 level and a random $\mathrm{GH}<1 \mathrm{ng} / \mathrm{mL}$ or nadir $\mathrm{GH}$ in OGTT $<0.4 \mathrm{ng} / \mathrm{mL}[9,10]$. We only selected patients who did not meet the criteria of cure postoperatively, 
who were treated with SSA for at least six months and had normal thyroid function (43 patients; 22 females/21 males). The patients were divided into three groups according to basal GH and IGF-1 after at least six months' treatment with SSA. If the GH level of a patient was less than $1 \mathrm{ng} / \mathrm{mL}$ and IGF-1 levels were within the age-sex adjusted normal range, each specific patient was categorized into the well-controlled group. The controlled group was defined as GH levels less than $1 \mathrm{ng} / \mathrm{mL}$ and IGF-1 levels were not within the age-sex adjusted normal range. Patients whose GH and IGF-1 levels were not within normal range were categorized into the active group. All patients were using the same SSA. All patients in the active group were using Sandostatin LAR $30 \mathrm{mg}$. Seven $(50 \%)$ patients used Sandostatin LAR 20 $\mathrm{mg}$ and 7 (50\%) used Sandostatin LAR $30 \mathrm{mg}$ in the well-controlled group. In the controlled group, there were 13 (61.9\%) patients using Sandostatin LAR $20 \mathrm{mg}$, and $8(38.1 \%)$ using Sandostatin LAR $30 \mathrm{mg}$. All patients were residing in areas with similar iodination status [11]. The prevalence of sonographic nodules in our country is $23.5 \%$ and $37.4 \%$ between the ages of 18 and 65 years and above 65 years, respectively [12]. Unfortunately, due to the retrospective nature of our study, data on urinary iodine content were unavailable for most patients. Free thyroxine (fT4), thyroid-stimulating hormone (TSH), antithyroid peroxidase (Anti-TPO), and antithyroglobulin (Anti-Tg) antibodies results of all patients were evaluated. All patients were euthyroid according to biochemical test results. The GH and IGF-1 levels were analyzed using chemiluminescence on an IMMULITE 2000 Xpi (Siemens Healthcare Diagnostics Inc.). Serum IGF-1 levels were compared with the agesex adjusted normal range. TSH and fT4 were measured using specific electrochemiluminescence immunoassays with a commercially available kit (Immulite 2000, Bio DPC, Los Angeles, CA, USA). The normal range for fT4 is $0.74-1.52 \mathrm{ng} / \mathrm{dL}$. TSH levels ranging between $0.55-$ $4.78 \mathrm{mIU} / \mathrm{L}$ were considered normal. The demographic data and medical history of all subjects were recorded, and anthropometric measurements were performed. Weight, height, waist circumference (WC), and hip circumference $(\mathrm{HC})$ were measured. Body mass index (BMI) was calculated by dividing the weight by the square of the height $\left(\mathrm{kg} / \mathrm{m}^{2}\right)$. Our study was performed in accordance with the recommendations of the Declaration of Helsinki. Ethics committee approval and written informed consent of the participants were obtained prior to the study.

\section{Thyroid ultrasound}

All patients underwent an evaluation of thyroid volume (TV) and total thyroid nodule volume (TTNV) using ultrasound. Thyroid ultrasonography (USG) was performed using high-resolution B-mode ultrasound images (EUB 7000 HV; Hitachi, Tokyo, Japan) with a $13-\mathrm{MHz}$ linear array transducer. The volume of each lobe was calculated using the ellipsoid model formula (length $\times$ thickness $\times$ width $\times$ 0.52) [13]. Nodule size was determined using the same formula as for TV [1]. Total TV $>18 \mathrm{~mL}$ in men and $>13 \mathrm{~mL}$ in women was considered as goiter [14]. TV was considered as the sum of the volumes of each lobe. The volume of each nodule was calculated using the formula used in the TV calculation. TTNV was considered as the sum of the volumes of all nodules. USG was not always performed by the same person on every patient because of the long duration of the follow-up; however, all examinations were recorded in the database of the Endocrinology Unit and were, for that reason, re-read and compared by the same person who was unaware of the therapy taken by the patients at the time of our retrospective evaluation.

\section{Statistical analysis}

Statistical analyses were performed using the Statistical Package for Social Sciences (SPSS) Version 15.0 softare package (SPSS, Inc, Chicago, IL, USA). The data are presented as a number of cases, mean, standard deviation, median with minimum and maximum. Normality was tested using the Kolmogorov-Smirnov and ShapiroWilk W test. One-way analysis of variance (ANOVA) with the Scheffe post hoc test or the Kruskal-Wallis H test with Bonferroni adjusted Mann-Whitney U test was used to compare the differences between three independent groups. The paired-samples $t$-test or Wilcoxon's signed-rank test was used to compare the differences between two measurements (beginning and end). A twosided $p$ value $<0.05$ was considered statistically significant for all analyses. Decrease in nodule volume as a dependent variable was modelled using binary logistic regression. Factors affecting thyroid nodule volume were taken as independent variables.

\section{Results}

Forty-three patients with acromegaly (21 males, 22 females, mean age $52.8 \pm 11.9$ years) who meet the inclusion criteria were enrolled in the study. The mean period of follow-up was $5.0 \pm 1.8$ years. The duration of treatment was found to be shorter in patients in the wellcontrolled group ( $4.1 \pm 1.7$ years) than in the active group $(6.5 \pm 2.3$ years) $(p=0.012)$. There was no difference between the controlled group (5.0 \pm 1.3 years) and the well-controlled group regarding treatment periods. The mean age, sex distribution, TSH, FT4 values, and initial TV did not differ statistically between the three 
Table 1 Characteristics of patients

\begin{tabular}{lccccc}
\hline Variables & Overall & Controlled & Well controlled & Active & $p$ \\
\hline Gender (male/female) & $21 / 22$ & $10 / 11$ & $6 / 8$ & $5 / 3$ & 0.667 \\
Age (years) & $52.8 \pm 11.9$ & $54.4 \pm 11.0$ & $52.8 \pm 15.0$ & $48.6 \pm 7.4$ & 0.510 \\
Treatment duration (years) & $5.0 \pm 1.8$ & $5.0 \pm 1.3$ & $4.1 \pm 1.7$ & $6.5 \pm 2.3$ & $\mathbf{0 . 0 1 2 ^ { \mathrm { a } }}$ \\
\hline Age at diagnosis (years) & $47.8 \pm 11.8$ & $49.4 \pm 11.0$ & $48.6 \pm 14.5$ & $42.1 \pm 7.4$ & 0.286 \\
Height $(\mathrm{cm})$ & $171.0 \pm 9.9$ & $171.8 \pm 10.1$ & $168.7 \pm 8.9$ & $173.0 \pm 11.5$ & 0.562 \\
Weight $(\mathrm{kg})$ & $86.9 \pm 9.6$ & $87.7 \pm 8.8$ & $83.6 \pm 7.7$ & $90.8 \pm 13.4$ & 0.342 \\
BMI (kg/m²) & $29.7 \pm 2.2$ & $29.8 \pm 2.4$ & $29.4 \pm 2.2$ & $30.2 \pm 2.0$ & 0.618 \\
TSH (IIU/m) & $2.0 \pm 1.1$ & $1.9 \pm 1.0$ & $2.1 \pm 1.1$ & $2.0 \pm 1.3$ & 0.912 \\
Free T4 (ng/dL) & $1.2 \pm 0.2$ & $1.2 \pm 0.2$ & $1.2 \pm 0.2$ & $1.3 \pm 0.2$ & 0.503 \\
\hline
\end{tabular}

Data were presented mean \pm standard deviation.

Statistically significant one is written in bold.

${ }^{a}$ Well Controlled Group versus Active Group

Table 2 GH, IGF-1, TV, TTNV and Nodule maximum diameter change before and after treatment

\begin{tabular}{|c|c|c|c|c|c|c|}
\hline Variables & & Overall & Well Controlled & Controlled & Active & $p^{\S}$ \\
\hline \multirow[t]{3}{*}{ GH } & beginning & $5.02[6.00]$ & $4.30[4.91]$ & $6.37[8.47]$ & $8.52[10.59]$ & $0.025^{\mathrm{a}}$ \\
\hline & end & $1.38[1.92]$ & $0.33[0.54]$ & $2.01[1.00]$ & $2.97[1.64]$ & $<0.001^{\text {b }}$ \\
\hline & $p^{\#}$ & $<0.001$ & $<0.001$ & 0.002 & 0.012 & \\
\hline \multirow[t]{3}{*}{ IGF-1\% ULN } & beginning & $522.0[437.0]$ & $428.0[357.5]$ & $516.5[386.3]$ & $1,066.0[493.0]$ & $0.002^{\mathrm{c}}$ \\
\hline & end & $218.0[168.0]$ & $179.0[60.0]$ & $281.5[95.8]$ & $515.5[332.3]$ & $<\mathbf{0 . 0 0 1}^{\mathrm{d}}$ \\
\hline & $p^{\#}$ & $<0.001$ & $<0.001$ & 0.001 & 0.025 & \\
\hline \multirow[t]{3}{*}{ Thyroid Volume (mL) } & beginning & $13.61[9.24]$ & $13.88[7.89]$ & $10.98[7.60]$ & $23.12[27.73]$ & 0.111 \\
\hline & end & $10.51[8.85]$ & $9.73[5.57]$ & $9.93[6.16]$ & $25.22[30.23]$ & $0.041^{\mathrm{a}}$ \\
\hline & $p^{\#}$ & 0.001 & $<0.001$ & 0.272 & 0.889 & \\
\hline \multirow[t]{3}{*}{ Total nodul Volume (mL) } & beginning & $0.34[1.01]$ & $0.44[0.75]$ & $0.18[1.28]$ & $0.77[1.46]$ & 0.887 \\
\hline & end & $0.23[1.05]$ & $0.23[0.73]$ & $0.13[1.54]$ & $1.03[1.88]$ & 0.894 \\
\hline & $p^{\#}$ & 0.102 & $<0.001$ & 0.959 & 0.028 & \\
\hline \multirow[t]{3}{*}{ Single nodul Maximum Diameter } & beginning & $8.00[9.00]$ & $8.00[9.00]$ & $8.00[\mathrm{~N} / \mathrm{A}]$ & $5.00[\mathrm{~N} / \mathrm{A}]$ & 0.442 \\
\hline & end & $7.00[7.00]$ & $7.00[7.00]$ & $7.00[\mathrm{~N} / \mathrm{A}]$ & $6.00[\mathrm{~N} / \mathrm{A}]$ & 0.695 \\
\hline & $p^{\#}$ & 0.763 & 0.180 & 0.655 & N/A & \\
\hline \multirow[t]{3}{*}{ Multipl nodul Maximum Diameter } & beginning & $10.50[6.50]$ & $10.00[6.00]$ & $13.50[11.0]$ & $12.00[5.75]$ & 0.919 \\
\hline & end & $10.50[9.00]$ & $8.00[6.50]$ & $15.50[11.0]$ & $12.50[6.25]$ & 0.335 \\
\hline & $p^{\#}$ & 0.015 & 0.002 & 0.892 & 0.041 & \\
\hline
\end{tabular}

Data were presented as median [IQR].

Statistically significant ones are written in bold.

\# Significant between beginning and end measurements

$\S$ Significant between cure, well controlled and active groups

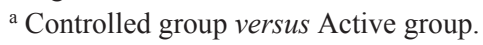

${ }^{\mathrm{b}}$ Controlled group versus Well controlled and Active groups.

${ }^{c}$ Active group versus Controlled and Well controlled groups.

${ }^{\mathrm{d}}$ All groups are statistically different each other.

N/A: Not Available, IGF-1\% ULN (Upper Limit of Normal)

groups (Tables 1,2). At the time of the thyroid examination, the mean IGF-1 level was $616.5 \pm 313.4 \mathrm{ng} / \mathrm{mL}$. On the date of diagnosis, the mean TV of the wellcontrolled, controlled, and active groups were 13.88
[7.89] (median, [range]), 10.98 [7.60] and 23.12 [27.73], respectively. There was a low correlation between TV in patients with acromegaly and basal IGF-1 levels $(r=$ $0.375, p=0.05)$ and BMI $(r=0.373, p=0.05)$. There 
Table 3 Nodule maximum diameter and frequency

\begin{tabular}{|c|c|c|c|}
\hline \multirow[b]{2}{*}{$n, \%$} & & SINGLE NODUL & MULTIPL NODUL \\
\hline & & $11(31.4 \%)$ & $24(68.6 \%)$ \\
\hline \multirow{3}{*}{ Maximum Diameter (mm) } & Baseline & $8.54 \pm 4.29$ & $13.34 \pm 7.84$ \\
\hline & Follow-up & $8.45 \pm 3.93$ & $12.17 \pm 7.07$ \\
\hline & $p$ & 0.763 & 0.015 \\
\hline
\end{tabular}

Table 4 Diameter change of soliter nodul

\begin{tabular}{lcccc}
\hline SINGLE NODUL $(n)$ & UNCHANGED & INCREASED & DECREASED & TOTAL \\
\hline$<1 \mathrm{~cm}$ & $3(100 \%)$ & $2(50 \%)$ & $2(50 \%)$ & $7(63.6 \%)$ \\
$\geq 1 \mathrm{~cm}$ & 0 & $2(50 \%)$ & $2(50 \%)$ & $4(36.4 \%)$ \\
TOTAL & 3 & 4 & 4 & 11 \\
\hline
\end{tabular}

$p=0.217<1 \mathrm{~cm}$ and $\geq 1 \mathrm{~cm}$ nodules similar to rates of change

Table 5 Diameter change of multipl nodul

\begin{tabular}{lcccc}
\hline MULTIPL NODUL $(n)$ & UNCHANGED & INCREASED & DECREASED & TOTAL \\
\hline$<1 \mathrm{~cm}$ & 0 & $3(33.3 \%)$ & $9(64.3 \%)$ & $12(50 \%)$ \\
$\geq 1 \mathrm{~cm}$ & $1(100 \%)$ & $6(66.7 \%)$ & $5(35.7 \%)$ & $12(50 \%)$ \\
TOTAL & 1 & 9 & 14 & 24 \\
\hline
\end{tabular}

$p=0.049$ The reduction rate of nodules $<1 \mathrm{~cm}$ was significantly higher.

was a highly significant correlation between $\mathrm{TV}$ in patients with acromegaly and duration of disease $(r=$ $0.715, p=0.01)$. TV decreased significantly in all patients (13.61 [9.24] to 10.51 [8.85], $p=0.001)$. TV decreased significantly in the well-controlled group (13.88 [7.89] to 9.73 [5.57], $p<0.001)$. TV did not change significantly in the controlled group (10.98 [7.60] to 9.93 [6.16], $p=0.272$ ) and in the active acromegaly group (23.12 [27.73] to 25.22 [30.23], $p=0.889)$.

The number of single nodules was 11 (31.4\%), and multiple nodules was 24 (68.4\%). The baseline single nodule maximum diameter (SNMD) was $8.54 \pm 4.29$ $\mathrm{mm}$, and at follow-up it was $8.45 \pm 3.93(p=0.763)$. The baseline multiple nodule maximum diameter (MNMD) was $13.34 \pm 7.84 \mathrm{~mm}$, and at follow-up it was 12.17 $\pm 7.07 \mathrm{~mm}(p=0.015)$ (Table 3$)$. The numbers of the affected nodules were specified (Tables 4, 5).

The prevalence of thyroid nodules was found as $81 \%$ in the well-controlled group, $85.7 \%$ in the controlled group, and $75 \%$ in the active group $(p>0.05)$. The TTNV decreased significantly in patients with wellcontrolled acromegaly $(0.44[0.75]$ to 0.23 [0.73], $p<$ 0.001 ) (Table 2). The TTNV did not change in controlled patients $(0.18$ [1.28] to 0.13 [1.54], $p=0.959)$; however, it increased in patients with active acromegaly $(0.77$ [1.46] to 1.03 [1.88], $p=0.028$ ) (Table 2 and Fig. 1 ). The MNMD decreased significantly in patients with wellcontrolled acromegaly $(10.00$ [6.00] to 8.00 [6.50], $p=$

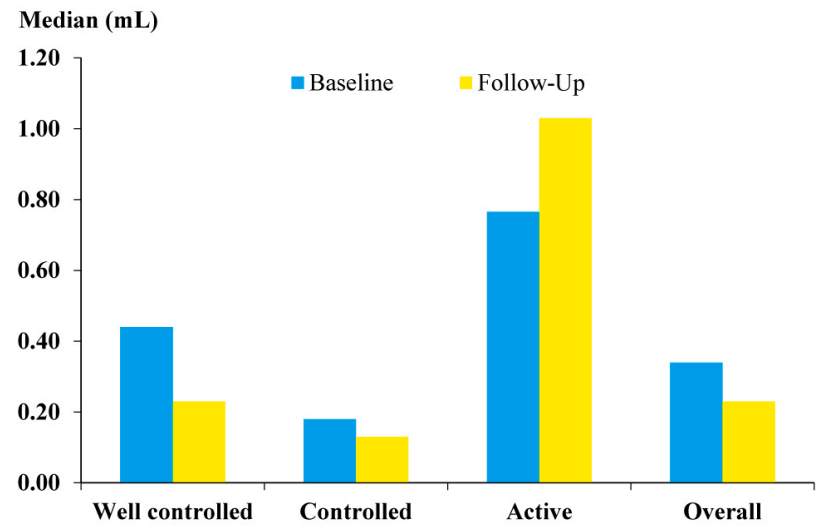

Fig. 1 TTNV change after SSA treatment

The TTNV decreased significantly in patients with wellcontrolled acromegaly. Although TTNV did not change in the controlled patients, it increased in patients with active acromegaly.

Abbreviations: TTNV, total thyroid nodule volume.

0.002). The MNMD did not change in controlled patients (13.50 [11.00] to 15.50 [11.00], $p=0.892)$; however, it increased in patients with active acromegaly (12.00 [5.75] to 12.50 [6.25], $p=0.041)$. The SNMD did not change (Table 2 ). In a binary logistic regression analysis, a decrease in IGF-1 levels (OR $=4.13$; 95\% CI: $[1.3-$ 8.34]; $p=0.011$ ) was found to be a significant predictor affecting decrease in thyroid nodule volume. Patients in the well-controlled group were associated with a 4.2-fold 
decrease in thyroid nodule volume $(\mathrm{OR}=4.2 ; 95 \% \mathrm{CI}$ : [3.44-6.57]; $p=0.009)$.

\section{Discussion}

In this study, we assessed TV, TTNV, and nodule maximum diameter change after SSA treatment in patients with acromegaly. Among 43 newly diagnosed acromegaly patients, who were followed up over a period of 5.0 \pm 1.8 years, we observed a significant decrease of TV in patients with well-controlled acromegaly. However, TV did not change in controlled patients and patients with active acromegaly. The TTNV decreased significantly in patients with well-controlled acromegaly. Although TTNV did not change in the controlled patients, it increased in patients with active acromegaly. MNMD decreased significantly in patients with well-controlled acromegaly. Although MNMD did not change in the controlled patients, it increased in patients with active acromegaly. SNMD did not change, likely because our patient number was too small.

GH replacement therapy in patients with GH deficiency was associated with increased thyroid volume. GH/IGF-1 signaling influences thyroid function and morphology. The suppression of the GH/IGF-1 signal may affect thyroid morphology [15]. In our study, we found that successful medical treatment in patients with acromegaly could reduce thyroid nodule volume. Our results are compatible with other studies $[3,6,7]$. To our knowledge this is the first study to evaluate TTNV and nodule maximum diameter change after SSA treatment in patients with acromegaly.

A thyroid nodule is a separate lesion in the thyroid gland that can be radiologically distinguished from the thyroid parenchyma [16]. IGF-1 stimulates synthesis of protein and DNA in thyrocytes, and stimulates the proliferation and differentiation of these cells $[17,18]$. Ongoing exposure to high serum IGF-1 levels may play a role in the development of thyroid nodules in patients with acromegaly [9]. Völzke et al. reported that high serum IGF-1 levels were associated with thyroid nodules [10]. In our study, TTNV decreased in patients with wellcontrolled acromegaly. Although TTNV did not change in controlled patients, it increased in patients with active acromegaly. The increase in TTNV without a change in TV in patients with active acromegaly may partly be explained by the impact of the sustained increase in IGF-1, which could be greater in the thyroid nodule when compared with normal thyroid parenchyma.

Nodule development is most commonly associated with initial IGF-1 levels in patients with acromegaly. For this reason, close monitoring of nodular thyroid disease is important in the surveillance of patients with active acromegaly. Thyroid nodules can vary dynamically according to acromegaly disease activity, and nodule growth should be closely monitored in patients with active acromegalic disease against the risk of malignancy [19]. In our study, the odds showed that a decrease in IGF-1 levels and the presence of the well controlled group were releated with an approximately four-fold decrease in thyroid nodule volumes. Therefore, close monitoring of nodular thyroid disease in patients with active acromegaly is very important using IGF-1.

Studies proved the presence of somatostatin receptors in healthy thyroid tissue as well as benign and malignant disease processes in the thyroid gland. Somatostatin receptor subtypes 2 and 5 are the most common somatostatin receptors found in the thyroid gland, subtypes 1 and 3 are rarely present, and subtype 4 is never found [20, 21]. Somatostatin (SRIH) inhibits basal and TSHinduced adenylate cyclase activity, in both normal and neoplastic human thyroid tissue $[22,23]$. Uberti et al. demonstrated that SRIH had a direct inhibitory action on growth by suppression of $3 \mathrm{H}$-thymidine incorporation in normal and goitrous human thyroid cell suspensions [24]. SRIH inhibited cell growth through suppression of the stimulatory effects of IGF-1 and TSH on a rat thyroid follicular cell line [25]. Thyroid size increases in active acromegaly and can be reduced with treatment that reduces IGF-1 levels to normal values [3, 7]. A similar reduction in TV was reported by Miyakawa et al. [6]. In our study, a significant IGF-1 reduction was seen all three groups, but a significant TV decrease was demonstrated only in patients with well-controlled acromegaly.

IGF-1 as a major factor that promotes thyroid growth, and differentiation is also produced locally by fibroblasts in the thyroid gland under the control of GH [26, 27]. Studies confirmed that patients with active acromegaly had higher thyroid volume as a result of increased IGF-1 levels. Whereas some studies observed a direct relationship between IGF-1, GH levels, and goiter [3, 6, 28, 29], some studies found no positive correlation between TV and IGF-1 or GH levels [7, 8, 30]. Although there was no correlation between GH levels and TV in our study, a highly significant correlation between TV and basal IGF-1 levels was found in the patients with acromegaly.

The influence of TSH on goiter formation in patients with acromegaly is complex [31]. An inverse correlation between thyroid volume and TSH levels was observed by some researches $[3,6]$. Takahashi et al. reported that IGF-1 had a minimal effect on Fischer rat thyroid follicle-5 (FRTL-5) cell lines when there was no TSH [30]. A study by Cheung et al. confirmed that GH therapy did not increase thyroid size in patients with hypopituitarism. The effect of IGF-1 on thyroid growth is not independent of TSH [32]. Cheung et al. propounded that 
TSH was considered to have a significant role in goiter development in an early stage of acromegaly. On the other hand, when thyroid autonomy has already developed as in a later stage, the presence of TSH is not essential for a further rise in TV [3]. In our study, there was no correlation between TV and TSH levels.

Unfortunately, due to the retrospective nature of study, a fixed standard follow-up protocol for thyroid nodules was not defined. The most important limitations of our study are the lack of a control group to compare nodular thyroid disease. Although there was no control group, it is known that the prevalance of sonographic nodules in our country is $23.5 \%$ and $37.4 \%$ between the age of 18 and 65 years and above 65 years, respectively (12). The incidence of nodular thyroid disease is well known in patients with acromegaly.

In conclusion, successful medical treatment of patients with active acromegaly decreases thyroid volume and thyroid nodule volume. Sustained exposure to IGF-1 may cause an increase in thyroid nodule volume in patients with acromegaly.

\section{Disclosure}

None of the authors has any potential conflicts of interest associated with this research.

\section{Conflict of Interest}

No conflict of interest among authors.

\section{References}

1. Cheung NW, Boyages SC (1997) The thyroid gland in acromegaly: an ultrasonographic study. Clin Endocrinol (Oxf) 46: 545-549.

2. Wolinski K, Czarnywojtek A, Ruchala M (2014) Risk of nodular thyroid disease and thyroid cancer in patients with acromegaly - meta-analysis and systematic review. PLoS One 9: e88787.

3. Tramontano D, Cushing GW, Moses AC, Ingbar SH (1986) Insulin-like growth factor-I stimulates the growth of rat thyroid cells in culture and synergizes the stimulation of DNA synthesis induced by TSH and Graves'-IgG. Endocrinology 119: 940-942.

4. Miyakawa M, Saji M, Tsushima T, Wakai K, Shizume K (1988) Thyroid volume and serum thyroglobulin levels in patients with acromegaly: correlation with plasma insulinlike growth factor I levels. J Clin Endocrinol Metab 67: 973-978.

5. Herrmann BL, Baumann H, Janssen OE, Görges R, Schmid KW, et al. (2004) Impact of disease activity on thyroid disease in patients with acromegaly: basal evaluation and follow-up. Exp Clin Endocrinol Diabetes 112: 225-230.

6. Cannavo S, Squadrito S, Finocchiaro MD, Curtol L, Almoto B, et al. (2000) Goiter and impairment of thyroid function in acromegalic patients: basal evaluation and follow-up. Horm Metab Res 32: 190-195.

7. Tita P, Ambrosio MR, Scollo C, Carta A, Gangemi P, et al. (2005) High prevalence of differentiated thyroid carcinoma in acromegaly. Clin Endocrinol (Oxf) 63: 161-167.

8. Völzke H, Friedrich N, Schipf S, Haring R, Lüdemann J, et al. (2007) Association between serum insulin-like growth factor-I levels and thyroid disorders in a population-based study. J Clin Endocrinol Metab 92: 4039-4045.

9. Giustina A, Barkan A, Casanueva FF, Cavagnini F, Frohman L, et al. (2000) Criteria for cure of acromegaly: a consensus statement. J Clin Endocrinol Metab 85: 526-
529.

10. Katznelson L, Laws ER Jr, Melmed S, Molitch ME, Murad MH, et al. (2014) Acromegaly: an endocrine society clinical practice guideline. J Clin Endocrinol Metab 99: 3933-3951.

11. Erdogan G, Erdogan MF, Emral R, Baştemir M, Sav H, et al. (2002) Iodine status and goiter prevalence in Turkey before mandatory iodization. $J$ Endocrinol Invest 25: 224228.

12. Turkey Endocrinology and Metabolism Society (2017) Guide to diagnosis and treatment of thyroid diseases. Türkiye Klinikleri, Ankara-Turkey. pp. 143-155 (In Turkish).

13. Vitti P, Rago T, Mazzeo S, Brogioni S, Lampis M, et al. (1995) Thyroid blood flow evaluation by color-flow Doppler sonography distinguishes Graves' disease from Hashimoto's thyroiditis. J Endocrinol Invest 18: 857-861.

14. Dogan S, Atmaca A, Dagdelen S, Erbas B, Erbas T (2014) Evaluation of thyroid diseases and differentiated thyroid cancer in acromegalic patients. Endocrine 45: 114-121.

15. Curto L, Giorinazzo S, Alibrandi A, Campenni A, Trimarchi F, et al. (2015) Effects of GH replacement therapy on thyroid volume and nodule development in $\mathrm{GH}$ deficient adults: a retrospective cohort study. Eur J Endocrinol 172: 543-552.

16. Haugen BR, Alexander EK, Bible KC, Doherty G, Mandel SJ, et al. (2016) American Thyroid Association Management Guidelines for adult patients with thyroid nodules and differentiated thyroid cancer. Thyroid 26: 1-133.

17. Kimura T, van Keymeulen A, Golstein J, Fusco A, Dumont JE, et al. (2001) Regulation of thyroid cell proliferation by TSH and other factors: a critical evaluation of in vitro models. Endocr Rev 22: 631-656.

18. Isozaki O, Santisteban P, Chan J, Grollman E, Kohn L (1987) Insulin and insulin-like growth factor-1 (IGF-I) regulate differentiation as well as growth in FRTL5 cells. Acta Endocrinol Suppl (Copenh) 281: 288-292. 
19. Dogansen SC, Salmaslioglu A, Yalin GY, Tanrikulu S, Yarman S, et al. (2018) Evaluation of the natural course of thyroid nodules in patients with acromegaly. Pituitary https: //doi.org/10.1007/s11102-018-0923-1.

20. Klagge A, Krause K, Schierle K, Steinert F, Dralle H, et al. (2010) Somatostatin receptor subtype expression in human thyroid tumors. Horm Metab Res 42: 237-240.

21. Druckenthaner M, Schwarzer C, Ensinger C, Gabriel M, Prommegger R, et al. (2007) Evidence for somatostatin receptor 2 in thyroid tissue. Regul Pept 138: 32-39.

22. Siperstein AE, Levin KE, Gum ET, Clark OH (1992) Effect of somatostatin on adenylate cyclase activity in normal and neoplastic thyroid tissue. World J Surg 16: 555 560.

23. Brandi ML, Toccafondi R (1985) Neuropeptidergic control of cyclic AMP accumulation in human thyroid cell. Peptides 6: 641-644.

24. degli Uberti EC, Hanau S, Rossi R, Piva R, Margutti A, et al. (1991) Somatostatin reduces 3H-thymidine incorporation and c-myc, but not thyroglobulin ribonucleic acid levels in human thyroid follicular cells in vitro. J Clin Endocrinol Metab 72: 1364-1371.

25. Tsuzaki S, Moses AC (1990) Somatostatin inhibits deoxyribonucleic acid synthesis induced by both thyrotropin and insulin-like growth factor-I in FRTL5 cells. Endocrinology 126: 3131-3138.

26. Bechtner G, Schopohl D, Rafferzeder M, Gärtner R,
Welsch U (1996) Stimulation of thyroid cell proliferation by epidermal growth factor is different from cell growth induced by thyrotropin or insulin-like growth factor I. Eur J Endocrinol 134: 639-648.

27. Westermark K, Karlsson FA, Westermark B (1983) Epidermal growth factor modulates thyroid growth and function in culture. Endocrinology 112: 1680-1686.

28. Wüster C, Steger G, Schmelzle A, Gottswinter J, Minne HW, et al. (1991) Increased incidence of euthyroid and hyperthyroid goiters independently of thyrotropin in patients with acromegaly. Horm Metab Res 23: 131-134.

29. Junik R, Sawicka J, Kozak W, Gembicki M (1997) Thyroid volume and function in patients with acromegaly living in iodine deficient areas. J Endocrinol Invest 20: 134137.

30. Kasagi K, Shimatsu A, Miyamoto S, Misaki T, Sakahara $\mathrm{H}$, et al. (1999) Goiter associated with acromegaly: sonographic and scintigraphic findings of the thyroid gland. Thyroid 9: 791-796.

31. Dąbrowska AM, Tarach JS, Kurowska M, Nowakowski A (2014) Thyroid diseases in patients with acromegaly. Arch Med Sci 10: 837-845.

32. Cheung NW, Lou JC, Boyages SC (1996) Growth hormone does not increase thyroid size in the absence of TSH: a study in adults with hypopituitarism. J Clin Endocrinol Metab 81: 1179-1183. 